\title{
Advanced opto-electronics materials by fullerene and acetylene scaffolding*
}

\author{
François Diederich $\ddagger$ \\ Department of Chemistry and Applied Biosciences, ETH Zürich, HCI G313, \\ $\mathrm{CH}-8093$ Zürich, Switzerland and NCCR "Nanoscale Science", Basel, Switzerland
}

\begin{abstract}
Functional $\pi$-systems with unusual opto-electronic properties are intensively investigated from both fundamental research and technological application viewpoints. This article reports on novel $\pi$-conjugated systems obtained by acetylenic and fullerene scaffolding. Linearly conjugated acetylenic nanorods, consisting of monodisperse poly(triacetylene) (PTA) oligomers and extending up to $18 \mathrm{~nm}$ length, were prepared to investigate the limits of effective conjugation and to explore at which length a monodisperse oligomer reaches the properties of an infinite polydisperse polymer. With the cyanoethynylethenes (CEEs), a powerful new class of electron acceptors is introduced that undergo intense intramolecular charge-transfer (CT) interactions with appended donors. Macrocyclic scaffolds with unusual opto-electronic properties are perethynylated dehydroannulenes, expanded radialenes, and radiaannulenes bearing peripheral dialkylanilino donor groups. Extended porphyrin-fullerene conjugates are investigated for their novel photophysical and efficient multicharge storage properties. Self-assembly of fullerenes and porphyrins, governed by weak interactions between the two components, leads to unprecedented nanopatterned surfaces that are investigated by scanning tunneling microscopy (STM).
\end{abstract}

Keywords: Acetylenes; fullerenes; porphyrins; conjugated polymers; donor-acceptor interactions; electrochemistry; electron transfer; annulenes; radialenes; radiaannulenes.

\section{INTRODUCTION}

Since the mid-1980s, we have pursued a synthesis-driven program aimed at producing carbon-rich materials with unusual opto-electronic properties using acetylenic scaffolding [1-3]. Objectives in this research are:

i. Expansion of the limits in size and complexity of stable monodisperse functional scaffolds that are accessible by organic synthesis and analytical characterization. A recent example illustrating the limits in stability is provided by an expanded octamethoxycubane with a $\mathrm{C}_{56}$ core, obtained by formal introduction of buta-1,3-diynediyl fragments as connectors between the corner carbon atoms of octamethoxycubane [4]. This compound is highly strained and explodes upon scratching.

ii. Advancement in an interplay between experiment and theory of the fundamental knowledge of $\pi$-electron delocalization in acetylenic molecular architecture expanding into one, two, and three dimensions. Examples of recent theoretical studies, which are pursued in collaboration, address

\footnotetext{
*Paper based on a presentation at the $17^{\text {th }}$ International Conference on Physical Organic Chemistry (ICPOC-17), Shanghai, China, 15-20 August 2004. Other presentations are published in this issue, pp. 1807-1921.

‡E-mail: diederich@org.chem.ethz.ch
} 
the aromaticity of expanded radialenes and their anions [5] and the remarkably low-activation free enthalpies $\left(\Delta G^{\neq}\right.$around $\left.84 \mathrm{~kJ} \mathrm{~mol}^{-1}\right)$ for cis-trans isomerization of tetraethynylbutatrienes (Fig. 1) [6].

iii. Development of new classes of chromophores with potential applications in opto-electronic devices. Work toward this objective is the subject of this review article. Specifically, the properties of $\pi$-conjugated molecular rods with a poly(triacetylene) (PTA) all-carbon backbone, of cyanoethynylethenes (CEEs), a new class of powerful electron acceptors, and of conjugated macrocycles with large acetylenic all-carbon cores are discussed.

iv. Exploration of the existence of novel molecular allotropes of carbon, different from fullerenes. Thus, cyclocarbons cyclo- $\mathrm{C}_{n}(n=18,24,30)$, with two orthogonal conjugated $\pi$-systems, were generated in the gas phase and shown to undergo coalescence reactions under fullerene formation $[7,8]$.

With the availability of fullerenes in bulk quantities since 1990 [9], fullerene-based advanced materials rapidly became another important target in our laboratory [10-12]. To produce fullerene building blocks for modular construction, we introduced the stereo- and regioselective tether-directed remote functionalization of the carbon spheres, leading to a new chemistry in three dimensions [13-15]. Taking advantage of versatile synthetic protocols [16,17], we prepared fullerene-based electrochemical ion sensors [18,19], solid-contact ion-selective electrodes [20], monolayers for photocurrent generation [21], fullerene-coated electrodes [22], fullerene-modified semiconductor surfaces [23], as well as polysiloxane-supported oxidation catalysts [24]. In this review, we describe our research in fullerene-porphyrin scaffolding, leading to molecular systems with unusual photophysical and redox properties and, in a very recent development, to the formation of nanopatterned surfaces by self-assembly.

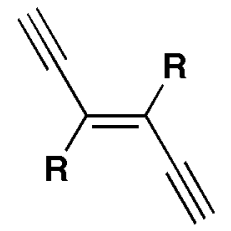

(E)-1,2-Diethynylethene

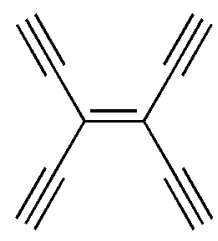

Tetraethynylethene

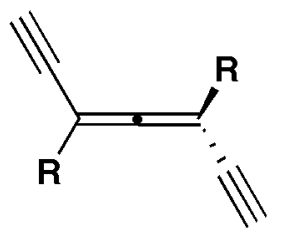

1,3-Diethynylallene

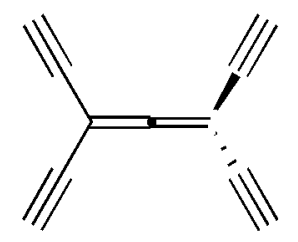

Tetraethynylallene

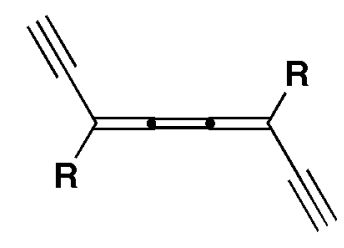

(E)-1,4-Diethynylbutatriene

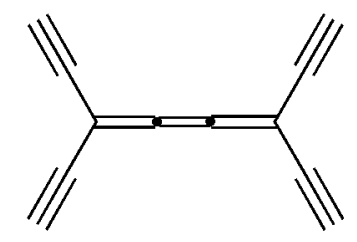

Tetraethynylbutatriene

Fig. 1 Building modules for acetylenic scaffolding.

\section{ACETYLENIC SCAFFOLDING}

\section{Versatile library of building blocks for acetylenic scaffolding}

Figure 1 features the all-carbon scaffolds of novel building modules prepared for acetylenic construction, by oxidative coupling [25], into one, two, and three dimensions. Nearly 100 differentially protected and functionalized tetraethynylethenes (TEEs, 3,4-diethynylhex-3-ene-1,5-diynes) and $(E)$-1,2-diethynylethenes (DEEs, $(E)$-hex-3-ene-1,5-diynes) have been prepared and used for the syn- 
thesis of advanced materials with unusual opto-electronic properties [26-28]. More recently, a synthesis of 1,3-diethynylallenes was introduced by regioselective $\mathrm{Pd}(0)$-catalyzed cross-coupling of silylprotected alkynes with substrates that bear bispropargylic leaving groups [29,30]. On the other hand, tetraethynylallenes remain elusive, despite much effort [31]. Good synthetic entries to 1,4-diethynylbutatrienes and tetraethynylbutatrienes have recently become available [6,32], and the chemistry of these novel modules, with remarkably low barriers to cis-trans isomerization, is now being explored.

\section{Conjugated oligomers with a poly(triacetylene) backbone and related derivatives}

A series of monodisperse, linearly conjugated PTA oligomers 1a-k (Fig. 2) extending up to $17.8 \mathrm{~nm}$ in length (24-mer) were prepared as models for the corresponding polydisperse infinite polymers [33-35] (for recent other work on PTA oligomers and polymers, see [36,37]). The effective conjugation length (ECL) at which saturation of properties occurs [38], was determined by several methods $\left({ }^{13} \mathrm{C} \mathrm{NMR}\right.$, electrochemical first reduction potentials, UV/vis and resonance-Raman spectroscopy, as well as measurement of the second hyperpolarizability $\gamma$ ) as $n_{\mathrm{ECL}} \approx 10$ monomeric repeat units. The X-ray crystal structure of the 3.2-nm-long tetramer was solved to clarify the conformational preferences of the PTA oligomers. In the solid state, the $\mathrm{C}=\mathrm{C}$ bonds all adopt the $s$-trans conformation with respect to the buta-1,3-diynediyl moieties. The $\pi$-conjugated system is perfectly planar.

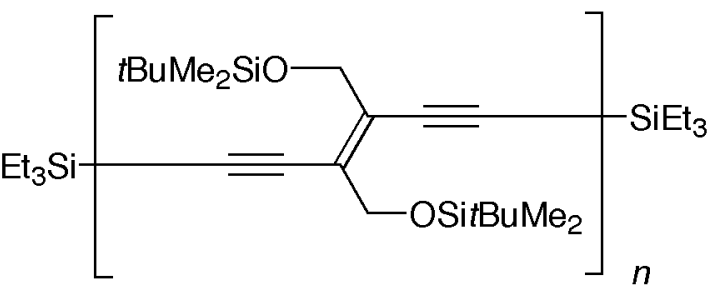

1a-k $n=1,2,3,4,5,6,8,10,12,16,24$

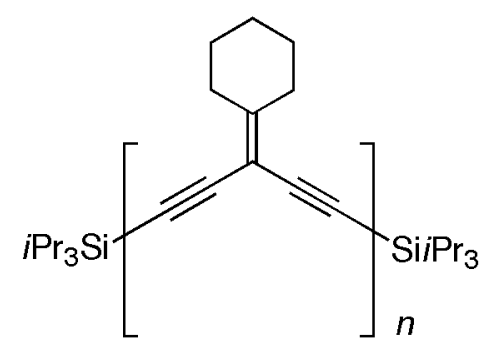

2a-d $n=2,3,4,8$

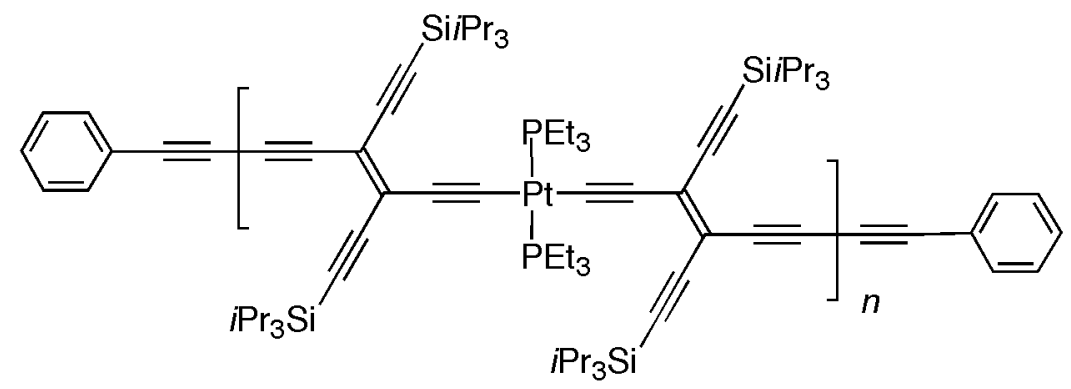

3a-f $n=1,2,3,4,5,6$

Fig. 2 Series of linearly conjugated monodisperse PTA oligomers 1a-k extending to $17.8 \mathrm{~nm}$ length, crossconjugated expanded dendralenes $\mathbf{2 a - d}$, and TEE-Pt hybrid molecular rods 3a-f in which the metal centers act as insulators, thereby preventing extended $\pi$-electron conjugation.

In contrast to the linearly conjugated PTA oligomers $\mathbf{1 a - k}$, which are highly stable below ca. $200{ }^{\circ} \mathrm{C}$ and can be stored in the air at ambient temperature for prolonged periods of time, the corresponding cross-conjugated expanded dendralenes 2a-d [39] are sensitive to both light and temperature 
and tend to decompose rapidly, an observation that still awaits good explanation (for other work on expanded dendralenes, see [40,41]). According to the UV/vis spectra, cross-conjugation seems effective in transmitting $\pi$-electron delocalization along the oligomeric backbone to some extent, although it is much weaker and less efficient than linear conjugation. Furthermore, semi-empirical calculations indicate that compounds $\mathbf{2 a - d}$ prefer nonlinear and nonplanar conformations.

We also prepared the series of Pt-bridged TEE oligomers 3a-f, expanding in length to $12.1 \mathrm{~nm}$ (hexameric 3f) [42]. Important information on the nature of the Pt-C(sp) bond was obtained: UV/vis spectral data as well as measurements of the second hyperpolarizability $\gamma$ by third-harmonic generation (THG) revealed a nearly complete lack of $\pi$-electron delocalization along the oligomeric backbone. The Pt-atoms act as true insulating centers, and the Pt-C(sp) bonds hardly possess any $\pi$-character [43].

\section{Cyanoethynylethenes: A new class of powerful electron acceptors}

New strong electron donors and acceptors that can be applied to molecular scaffolding are of substantial interest for tuning opto-electronic properties of advanced materials. With their many $\mathrm{C}(\mathrm{sp})$ centers in their all-carbon cores, TEEs and DEEs as well as 1,3-dialkynylated and 1,1,4,4-tetraalkynylated butatrienes (Fig. 1) are good electron acceptors. Their conjugation to strong electron donors such as $\mathrm{N}, \mathrm{N}$-dimethylanilino (DMA) residues has generated compounds featuring not only strong intramolecular charge-transfer (CT) interactions [44], but also potent second- [45] and third-order [2] nonlinear optical properties.

One of the best acceptors, of course, is tetracyanoethene (TCNE, $E_{0}=-0.32 \mathrm{~V} \mathrm{in} \mathrm{CH}_{2} \mathrm{Cl}_{2}$, all potentials in this review are from cyclic voltammetry (CV) and refer to the ferrocene/ferricinium couple $\mathrm{Fc} / \mathrm{Fc}^{+}$). However, it does not contain vectors for functionalization and incorporation into larger molecular frameworks. This led us to develop a class of TEE-TCNE hybrids, the CEEs of which only two derivatives had been previously reported [46,47].

The first representatives of the CEEs (4a-f) are depicted in Fig. 3 [48]. Electrochemical investigations showed that the first $1-\mathrm{e}^{-}$reduction becomes increasingly facilitated by the replacement of acetylene moieties in TEE by isoelectronic cyano groups, with $\mathbf{4} \mathbf{f}$ approaching the acceptor strength of TCNE while profiting from two additional anchor points for further functionalization. The increase in electron acceptor strength upon substituting one $\mathrm{RC} \equiv \mathrm{C}-$ by a $\mathrm{N} \equiv \mathrm{C}$ - group is, on average, $380 \mathrm{mV}$, whereas replacing one $\mathrm{RC} \equiv \mathrm{C}-\mathrm{C}-\mathrm{C} \equiv \mathrm{CR}$ group with $\mathrm{NC}-\mathrm{C}-\mathrm{CN}$ increases the average electron acceptor strength by $830 \mathrm{mV}$ !

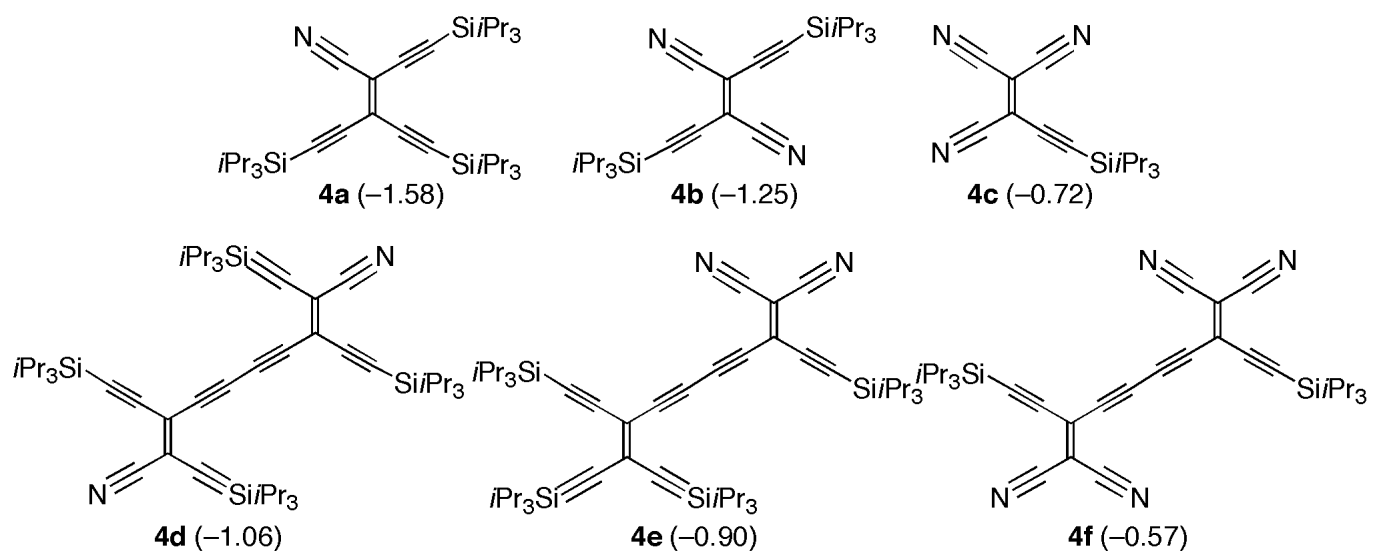

Fig. 3 Monomeric and dimeric CEEs. Given in parenthesis are the reversible first $1-\mathrm{e}^{-}$reduction potentials (V) in $\mathrm{CH}_{2} \mathrm{Cl}_{2}$ vs. $\mathrm{Fc} / \mathrm{Fc}^{+}$. For comparison, $E_{0}$ of tetrakis(trialkylsilylated) TEE: $-1.96 \mathrm{~V}$; of hexakis(trialkylsilylated) TEE dimer: $-1.52 \mathrm{~V}$. 
Upon attachment of DMA donor groups to the residual acetylenic anchor points in the CEEs, chromophores such as 5a-g (Fig. 4) with excellent advanced materials properties were obtained [49]:

i. $\quad$ Very strong intramolecular charge transfer occurs, leading to CT bands (which disappear upon DMA-protonation and reappear unchanged upon reneutralization) with maxima shifted strongly bathochromically from those of the donor (DMA)-acceptor ( $p$-nitrophenyl)-substituted TEEs. Large bond length changes in the DMA moieties toward quinoidal character are seen in the X-ray crystal structures of $\mathbf{5 a}$ and $\mathbf{5 c}$ and further support the strong intramolecular CT character.

ii. In contrast to the previously exploited TEEs $[2,44]$, compounds such as $\mathbf{5 a}$ and $\mathbf{5 b}$ can be sublimed undecomposed at $100{ }^{\circ} \mathrm{C} / 0.1$ Torr, making them quite suitable for the preparation of thin films by vapor deposition. Thus, a thin film of 5a was formed and shown to display a high principal NLO coefficient $d 11$ of $2.5 \mathrm{pm} / \mathrm{V}$.

iii. In first investigations, the two-photon absorption (TPA) cross-section of $\mathbf{5 b}$ was determined to be three times higher $\left(8.8 \times 10^{-49} \mathrm{~cm}^{4} \mathrm{~s}_{\text {photon }}^{-1}\right.$ at $900 \mathrm{~nm}$ in 1,1,2,2-tetrachloroethane) than the value measured for the standard reference AF-50, clearly illustrating the high potential of small CEE molecules for opto-electronic applications.

iv. In contrast to the donor-acceptor-substituted TEEs, some of the donor-substituted CEEs, such as $\mathbf{5 c}$, exhibit intense fluorescence emission.<smiles>C=C(C#Cc1ccc(N(C)C)cc1)C(C#N)=C(C#N)C#Cc1ccc(N(C)C)cc1</smiles><smiles>CN(C)c1ccc(C#CC(C#CC#CC(C#N)=C(C#N)C#N)=C(C#N)C#N)cc1</smiles>

$5 d(600 \mathrm{~nm})$<smiles>CC(C)[AsH2]C#CC(C#N)=C(C#C[SiH2])C#Cc1ccc(N(C)C)cc1</smiles>

$5 e(464 \mathrm{~nm})$

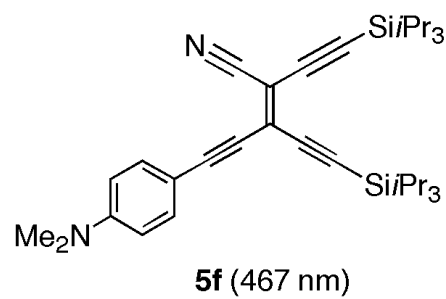

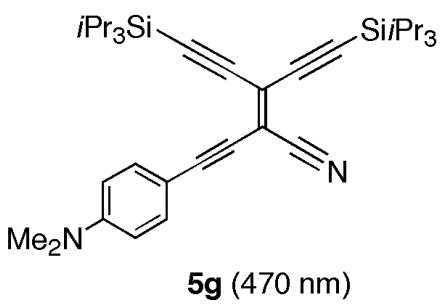

Fig. 4 Examples of donor-substituted CEEs. Given in parentheses are the longest-wavelength absorption maxima in $\mathrm{CHCl}_{3}$. 
In many reports in the literature, intense CT bands in the UV/vis spectra are taken as an indication of strong donor-acceptor interactions, and it is assumed that more effective conjugation pathways generally lead to a bathochromic shift of the lowest-energy transition band. In contrast, the interpretation of the UV/vis spectra of the donor-substituted CEEs 5e-g gives misleading indications on the effectiveness of the conjugation pathways [50]. All three compounds feature almost identical spectra in $\mathrm{CHCl}_{3}$, with the CT band of the cross-conjugated derivative $\mathbf{5 g}$ appearing at lower energy $\left(\lambda_{\max }=\right.$ $470 \mathrm{~nm}, 2.64 \mathrm{eV})$ than the maxima of the linearly conjugated cis $\left(\mathbf{5 f}, \lambda_{\max }=467 \mathrm{~nm}, 2.65 \mathrm{eV}\right)$ and trans $\left(5 \mathrm{e}, \lambda_{\max }=464 \mathrm{~nm}, 2.67 \mathrm{eV}\right)$ derivatives. This similarity in the position of the CT band was not expected since it is well established - through experiment and theory-that cross-conjugation is less efficient than linear conjugation. Computational studies actually revealed that within this series of constitutional isomers, the variance in the lowest-energy transitions is caused by differences in the HOMO (highest occupied molecular orbital) energy, which is highest in the cross-conjugated system. It became apparent, therefore, in this investigation that the correlation between the position of $\lambda_{\max }$ in the UV/vis spectra and the effectiveness of different conjugation pathways is not always valid; a conclusion also reached by others [51,52]. For compounds with strong donor and acceptor moieties, the $\lambda_{\max }$ in the $\mathrm{UV} / \mathrm{vis}$ spectrum should only be considered as a measure of the change of the degree of CT in the transition from the ground state to the excited state, and should not be used for the study of conjugation effectiveness. For the evaluation of the latter, methods describing the ground state, such as thermochemistry, X-ray analysis, ${ }^{13} \mathrm{C}$ NMR spectroscopy, and ground-state and energy calculations, are much more suitable.

\section{Large all-carbon sheets with peripheral donor groups}

Shape-persistent, conjugated macrocycles with all-carbon skeletons are of interest to many research groups [53-64]. In our research aimed at producing large all-carbon sheets [7], we have become interested in three classes of macrocycles, perethynylated dehydroannulenes [65], perethynylated expanded radialenes [66], and perethynylated radiaannulenes [68]. The latter are novel macrocyclic chromophores that can be viewed as hybrids between expanded dehydroannulenes and expanded radialenes. The three classes of macrocycles all are strong electron acceptors due to the presence of a large number of $\mathrm{C}(\mathrm{sp}$ )-atoms in their all-carbon cores [28]. The physical properties of these compounds are strongly enhanced upon introduction of peripheral $N, N$-dialkylanilino donor groups. These substituents greatly augment solubility and stability and undergo strong intermolecular CT interactions with the all-carbon cores.

A very tedious, multistep synthesis of $c i s$-bisdeprotected TEEs, passing via several unstable intermediates, prevented until recently the preparation of functionalized derivatives of the perethynylated antiaromatic octadehydro[12]- and aromatic dodecadehydro[18]annulenes we had reported more than 10 years ago [68]. A recently developed simple photochemical route now enabled us to prepare and study derivatives 6 and 7, bearing lateral DMA substituents (Fig. 5) [69,70].

With their peripheral donor groups and the electron-accepting macrocyclic perimeters, the novel chromophores undergo intense intramolecular CT interactions. Interestingly, both antiaromatic (6) and aromatic (7) annulenes displayed identical maxima of their longest-wavelength CT band $\left(\lambda_{\max }=\right.$ $518 \mathrm{~nm}$ ), demonstrating that both are equally capable of mediating $\pi$-electron donor-acceptor conjugation. Only the intensity of the CT band in $7\left(\varepsilon=105200 \mathrm{M}^{-1} \mathrm{~cm}^{-1}\right)$ is higher than in $6\left(\varepsilon=35100 \mathrm{M}^{-1}\right.$ $\mathrm{cm}^{-1}$ ), due to the larger number of donor-acceptor conjugation pathways in 7 . We consider these results rather surprising, since one might expect the $\mathrm{CT}$ to be more efficient in the [12]annulene as the uptake of electrons reduces the antiaromaticity, whereas in the case of the [18]annulene, the uptake of electrons is accompanied by a loss of aromaticity. Clearly, the nature of these electronic transitions is governed by other factors than aromaticity/antiaromaticity. 


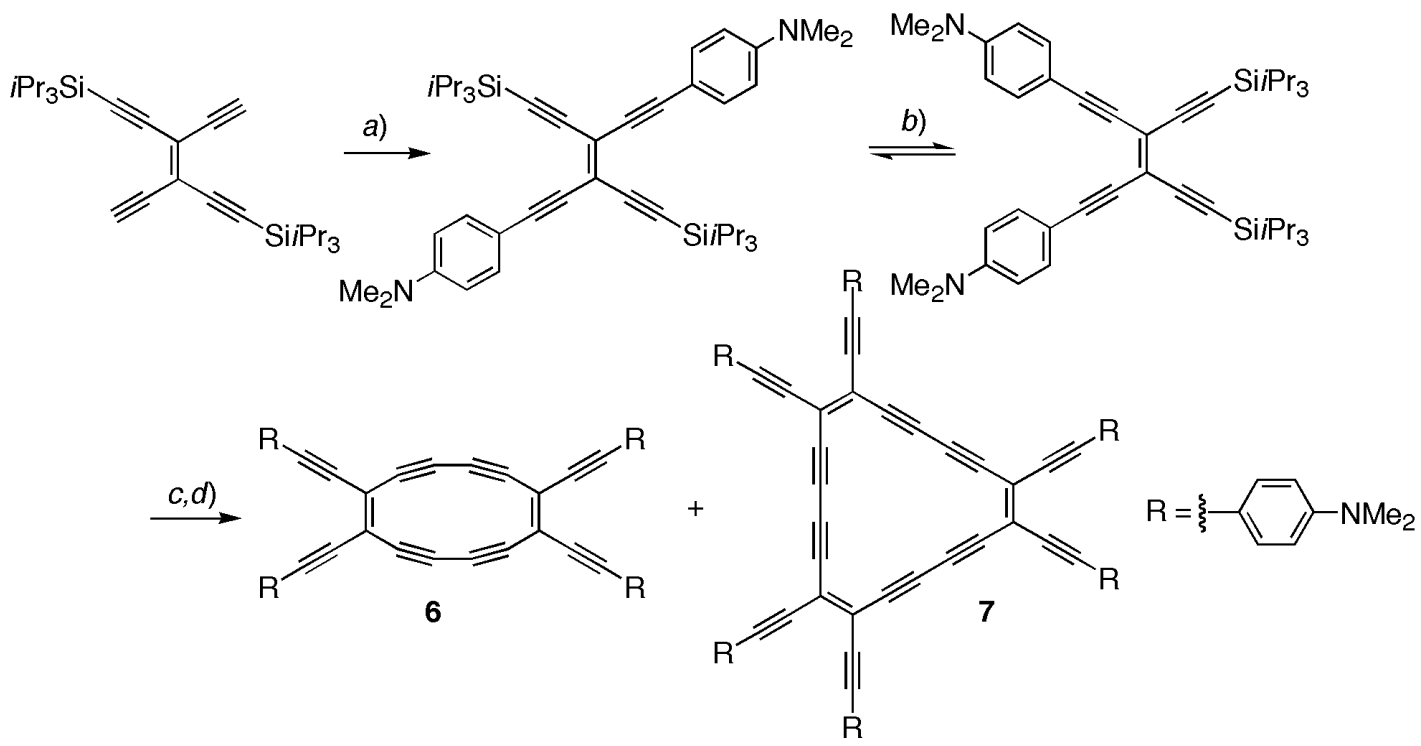

Fig. 5 Synthesis of the donor-substituted dehydroannulenes 6 and 7. (a) 4-Iodo- $N, N$-dimethylaniline, $\left[\mathrm{PdCl}_{2}\left(\mathrm{PPh}_{3}\right)_{2}\right], \mathrm{CuI}, i \mathrm{Pr}_{2} \mathrm{NH}, 20{ }^{\circ} \mathrm{C}, 14 \mathrm{~h}, 85 \%$; (b) Et $2 \mathrm{O}, \mathrm{h} v, 20{ }^{\circ} \mathrm{C}, 2 \mathrm{~h}, 41 \%$; (c) $\mathrm{Bu}_{4} \mathrm{NF}, \mathrm{THF}, 0{ }^{\circ} \mathrm{C}, 10 \mathrm{~min}$; (d) $\mathrm{CuCl}, N, N, N^{\prime}, N^{\prime}$-tetramethylethylenediamine (TMEDA), $\mathrm{O}_{2}$, acetone $20{ }^{\circ} \mathrm{C}, 2 \mathrm{~h}, 2 \%(6), 22 \%$ (7).

In 1993, we had reported the first examples of the expanded radialenes [71] and had since then continued investigating the opto-electronic properties of these novel macrocyclic chromophores [72] (for other work, see [54,55]). In continuation of this work, three series of perethynylated expanded $[n]$ radialenes $(n=3,4,6,8) \mathbf{8 a - c}, \mathbf{9 a}-\mathbf{d}$, and 10a-d with differently functionalized peripheral phenyl rings were prepared and subjected to comprehensive physical-organic study (Fig. 6). For the expanded [6]radialene $\mathbf{8 b}$ with a central $\mathrm{C}_{60}$ core, $\mathrm{X}$-ray crystal structure analysis revealed a nonplanar, perfectly chair-like transition. As in the dehydroannulenes, attachment of peripheral $N, N$-dialkylanilino groups leads to intense intramolecular CT transitions.
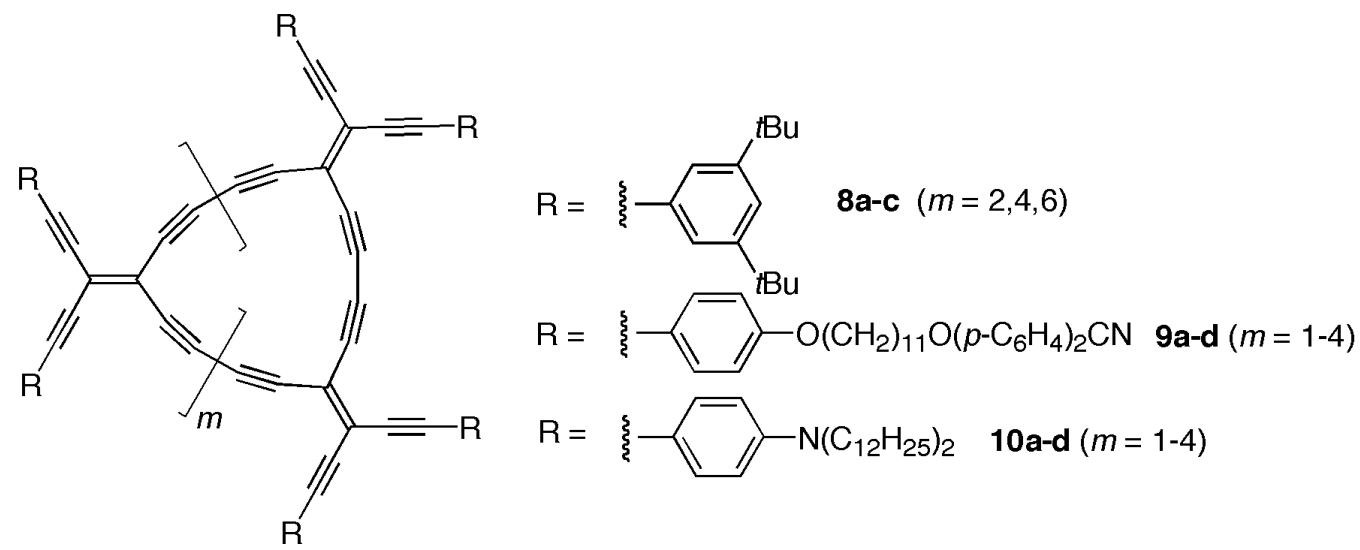

Fig. 6 Perethynylated expanded radialenes 8-10.

Macrocyclic cross-conjugation, as measured by the onset of the UV/vis absorption, was found to become increasingly efficient with increasing donor-acceptor polarization. In particular, macrocyclic conjugative effects seem to be quite effective at the stage of the mono-anions. Electrochemical meas- 
urements showed that the expanded [3] and [4]radialenes are reduced at strongly anodically shifted potentials relative to suitable acyclic comparison compounds; that is, the macrocyclic cross-conjugated cores can better accommodate electrons than their linear counterparts. A comprehensive theoretical study, including calculation of structures and electronic properties at the density functional theory (DFT) level, using the B3PW91 functional, calculations of the nucleus-independent chemical shift (NICS) values, and electron localization function (ELF) analysis, supports these conclusions from the experimental work [5]. The exceptional ability of the expanded [3] and [4]radialenes to accommodate electrons is clearly promoted by aromaticity enhancement in the resulting mono-anions.

By combining the structural features of expanded dehydroannulenes and expanded radialenes, a new class of planar, highly conjugated all-carbon macrocycles $(\mathbf{1 1 a}-\mathbf{c}, \mathbf{1 2 a}, \mathbf{b})$, which we christened "radiaannulenes", was recently prepared (Fig. 7) [67,70]. Compound 11a was characterized by X-ray crystallography as a planar, substantially strained compound. Strain in the 16-membered ring is expressed by bending the three buta-1,3-diynediyl moieties, with $\mathrm{C} \equiv \mathrm{C}-\mathrm{C}(\mathrm{sp})$ angles as low as $169.2^{\circ}$, by a deviation of the $\mathrm{C}(\mathrm{sp})-\mathrm{C}\left(\mathrm{sp}^{2}\right)-\mathrm{C}(\mathrm{sp})$ angles at the exocyclic ethylene units from ideally $120^{\circ}$ to ca. $111^{\circ}$, and in particular by the bending of the macrocyclic $\mathrm{C} \equiv \mathrm{C}-\mathrm{C}\left(\mathrm{sp}^{2}\right)$ angles from ideally $180^{\circ}$ to ca. $164^{\circ}$.

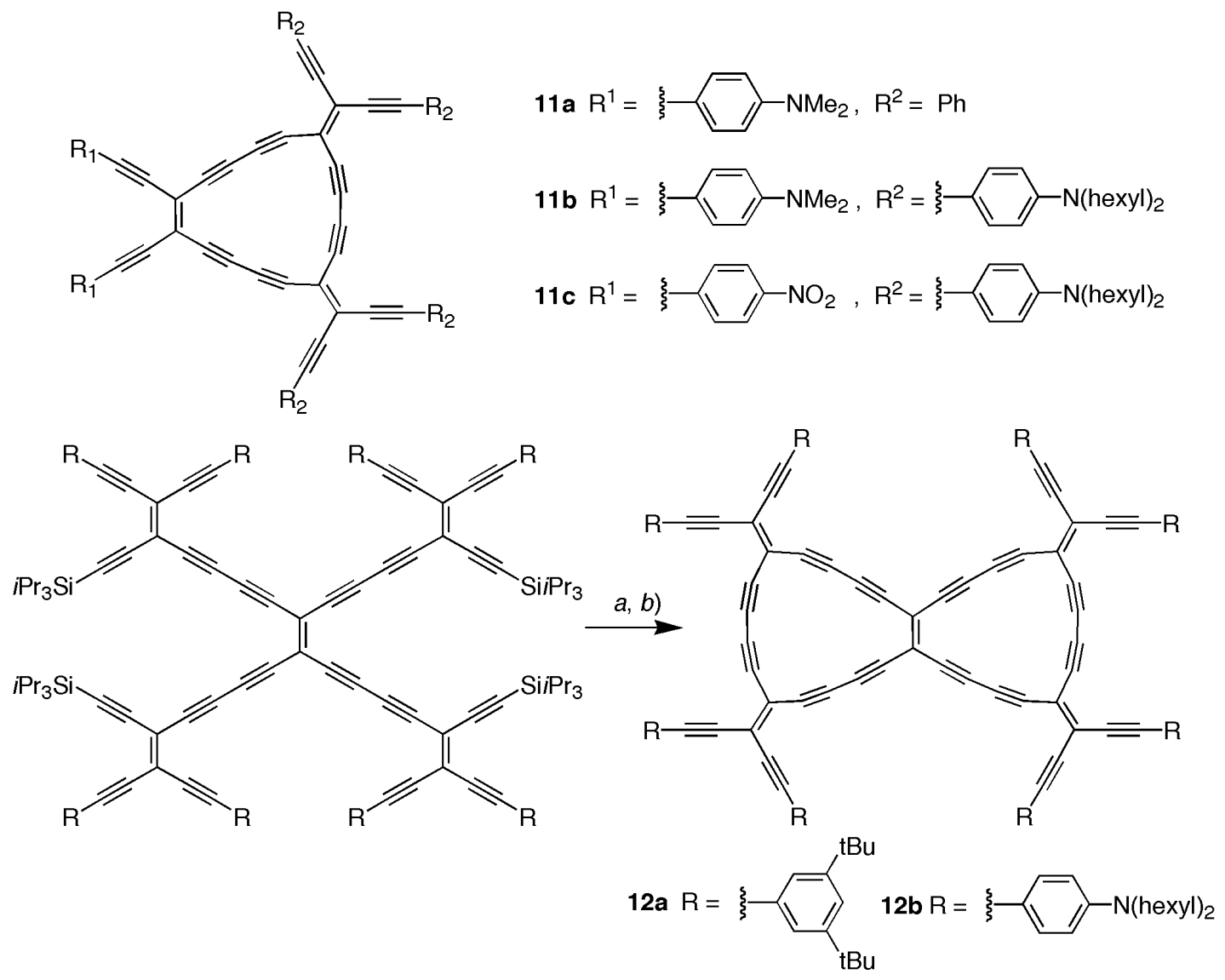

Fig. 7 Synthesis of the radiaannulenes 11 and 12. (a) $\mathrm{Bu}_{4} \mathrm{NF}$, THF, $0{ }^{\circ} \mathrm{C}, 10 \mathrm{~min}$; (b) $\mathrm{CuCl}$, TMEDA, $\mathrm{O}_{2}$, acetone/PhH/THF, $20{ }^{\circ} \mathrm{C}, 2 \mathrm{~h}, 88 \%$ (12a), $15 \%$ (12b).

The opto-electronic properties of this novel class of chromophores are very promising. The central all-carbon cores $\left(\mathrm{C}_{50}\right.$ core in macrobicycles 12a,b) are outstanding electron acceptors, with the first 
$1-\mathrm{e}^{-}$reduction of 12a occurring at $-0.83 \mathrm{~V}$ (THF), which is much more anodic than the first reduction of buckminsterfullerene $\mathrm{C}_{60}(-1.02 \mathrm{~V})$, which is touted as a very good electron acceptor. Lateral functionalization with dialkylanilino donor moieties leads to strong intramolecular CT, with the end-absorption of $\mathbf{1 2 b}$ being shifted toward the near infrared (NIR) $(850 \mathrm{~nm}, 1.46 \mathrm{eV})$. Given the high environmental stability of the compounds already in hand, we should be able to prepare in future work even larger radiaannulenes, with all-carbon cores of 100 and more $\mathrm{C}$-atoms.

\section{EXTENDED PORPHYRIN-FULLERENE CONJUGATES}

Porphyrin-fullerene conjugates are intensely investigated as electron donor-acceptor dyads and triads, in which porphyrin donors lose their characteristic luminescence properties as a result of light-induced energy and/or electron transfer to the fullerene acceptor [73-78]. On the other hand, Osuka and coworkers have introduced new oligoporphyrin arrays in which the porphyrin rings are either linked by single bonds in a biaryl-type fashion or triply fused under generation of porphyrin sheets with exceptional electronic properties [79-81]. Combining fullerenes with these novel oligoporphyrins, we prepared and investigated the series of conjugates 13a-c and 14 (Fig. 8) [82-84].

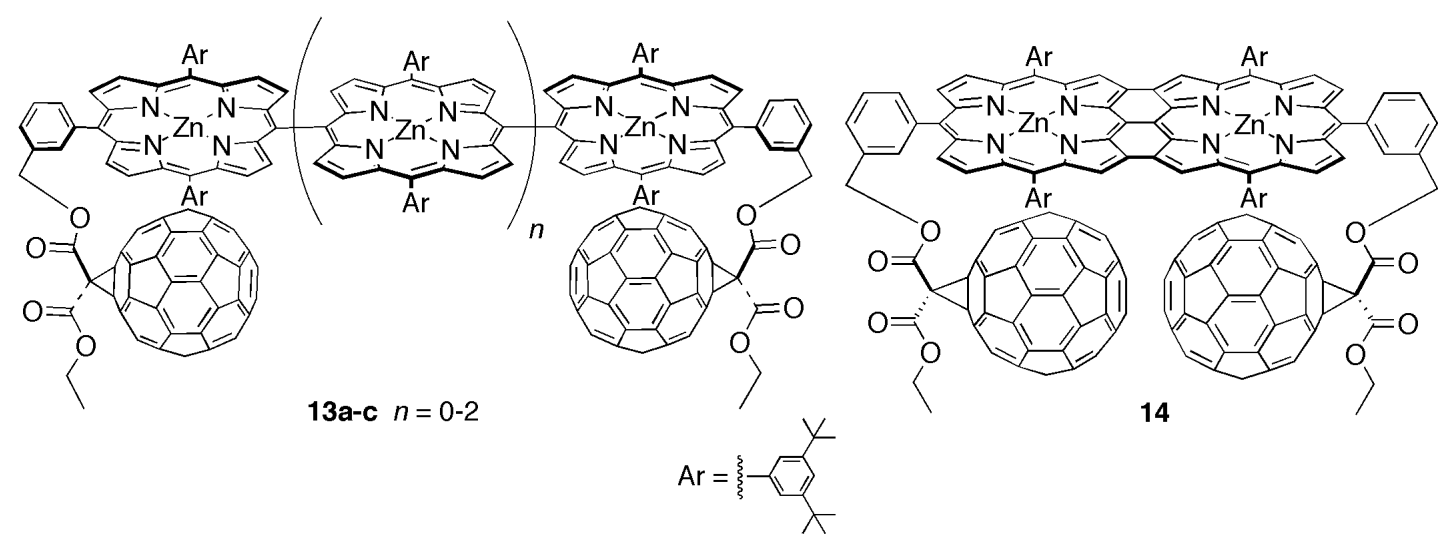

Fig. 8 Extended porphyrin-fullerene nanoarrays.

In the preferred conformations of 13a-c, each fullerene sits atop a porphyrin ring [82,85,86]. By variable-temperature ${ }^{1} \mathrm{H}$ NMR spectroscopy, the attractive interaction between a fullerene and a tangential porphyrin in perdeuterated toluene was determined as $12 \mathrm{~kJ} \mathrm{~mol}^{-1}$. In contrast, the interchromophoric interaction in $\mathbf{1 4}$ is only very weak.

Exceptional electrochemical properties were determined for the diporphyrin conjugates 13a and 14. They undergo 15 reversible electron transfers in CV and differential pulse voltammetry experiments. Four electrons can be removed from the diporphyrin, and each dyad can be charged with 11 electrons, 3 of which are localized on the diporphyrin and 4 on each fullerene sphere [83]. The electrochemical HOMO-LUMO gap ( $E_{1} \mathrm{Ox}_{-} E_{1}{ }^{\mathrm{Red}}$ ) for $\mathbf{1 4}$ is determined as $1.02 \mathrm{~V}$, which is substantially lower than the gap recorded for 13a $(1.35 \mathrm{~V})$; this difference is important for the explanation of the dramatically different photophysical properties of the two conjugates 13a and $\mathbf{1 4}$.

Dyad 13a with a singly bridged diporphyrin shows a photophysical behavior similar to that reported in the literature for other porphyrin-fullerene donor-acceptor systems [73-78,86]. Upon excitation of the diporphyrin at $530 \mathrm{~nm}$ in toluene at $298 \mathrm{~K}$, the porphyrin luminescence is quenched due to photoinduced electron transfer to the fullerenes under formation of a luminescent CT state with a lifetime of $630 \mathrm{ps}$ and an emission maximum at $953 \mathrm{~nm}$. In sharp contrast, photoexcitation of the fullerene spheres in dyad 14 at $330 \mathrm{~nm}$ (in toluene at $298 \mathrm{~K}$ ) results in quantitative sensitization, presumably via 
energy transfer, of the very short-lived (4.5 ps) and low-lying (about $1 \mathrm{eV}$, see electrochemistry results above) diporphyrin singlet. This low-lying singlet state acts as an energy sink for the higher electronic levels, and porphyrin emission $\left(\lambda_{\mathrm{em}}=1092 \mathrm{~nm}\right)$ is observed with a quantum yield similar to that measured for the emission of the triply fused diporphyrin without fullerenes attached. Such photophysical behavior had not been previously observed for any fullerene-porphyrin dyad or triad.

Finally, we investigated the self-assembly of porphyrin derivatives 15-17 (Fig. 9) with $\mathrm{C}_{60}$ on silver surfaces by means of scanning tunneling microscopy (STM) [87]. Upon evaporation of pristine $\mathrm{C}_{60}$ on preorganized porphyrin monolayers, unprecedented one- and two-dimensional fullerene patterns were obtained [88]. The arrangement of the fullerene molecules on the patterned layers is controlled by the porphyrin structure: evaporation of $\mathrm{C}_{60}$ on surfaces of porphyrin $\mathbf{1 5}$ generates a mode of self-assembly that differs strongly from that observed on surfaces of $\mathbf{1 6}$ and 17. At this stage, we hypothesize that the observed mode of self-assembly arises from a delicate balance between the fullerene-porphyrin interactions and the conformational motion within the underlaying porphyrin layer. Systematic variation of the structural and electronic characteristics of the porphyrin should shed further light into the mechanisms of patterned porphyrin surface formation and porphyrin-fullerene self-assembly. Most remarkably, $\mathrm{C}_{60}$ can be reversibly repositioned with the STM tip on surfaces of 16, while the ordered diporphyrin layer is not affected by the fullerene relocalization. This supramolecular approach holds enormous potential for the fabrication of laterally addressable single-molecule devices.

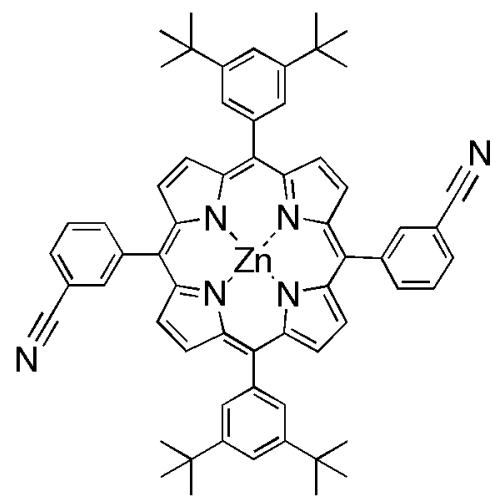

15

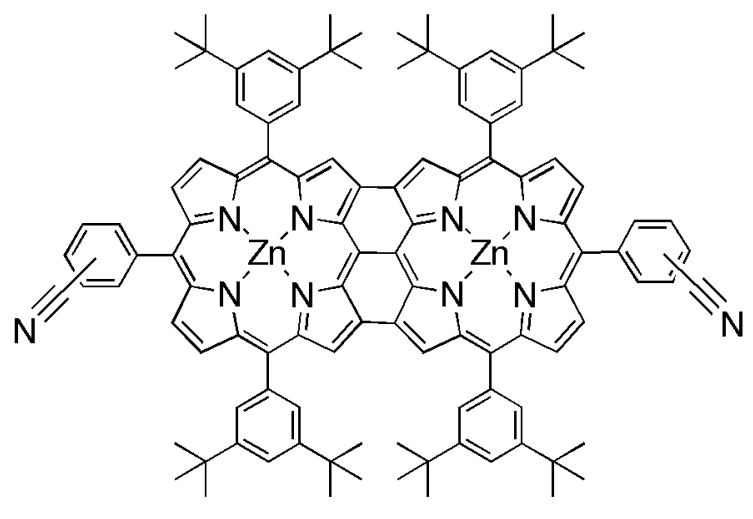

16 meta-CN

\section{7 para-CN}

Fig. 9 Porphyrin derivatives 15-17 undergo self-assembly with $C_{60}$ under formation of nanopatterned surfaces.

\section{CONCLUSIONS}

The research described in this article illustrates how acetylenic and fullerene scaffolding in one, two, and three dimensions continues to expand our knowledge of structure and function of carbon-rich matter. Opto-electronic properties highlighted are the ECL in linearly conjugated PTA oligomers and polymers, the powerful intramolecular CT interactions in donor-substituted CEEs and donor-substituted allcarbon macrocycles such as perethynylated dehydroannulenes, expanded radialenes, and radiannulenes, the efficiency of macrocyclic cross-conjugation, and the exceptional redox and photophysical behavior of oligoporphyrin-fullerene conjugates. Finally, self-assembly of fullerenes on nanopatterned porphyrin surfaces and reversible manipulation of the carbon spheres on the organic layers provide fascinating perspectives for future single-molecule device fabrication. While most of the advanced materials described in this article are of multinanometer size, such as the PTA rods, the acetylenic macrocycles, and the oligoporphyrin-fullerene conjugates, the exceptional properties of CEEs and their 
donor-substituted derivatives, such as formation of ordered NLO-active films by molecular beam epitaxy, also demonstrate the continuing potential of highly programmed small molecules for use as advanced materials. Clearly, many more structures—small and large ones—and functions remain to be discovered in this field.

\section{ACKNOWLEDGMENTS}

We thank the NCCR "Nanoscale Science", the Swiss National Science Foundation, the ETH Research Council, and the German Fonds der Chemischen Industrie for continuing support of this work.

\section{REFERENCES}

1. F. Diederich. Chem. Commun. 219-227 (2001).

2. R. R. Tykwinski, U. Gubler, R. E. Martin, F. Diederich, C. Bosshard, P. Günter. J. Phys. Chem. B 102, 4451-4465 (1998).

3. M. B. Nielsen and F. Diederich. In Modern Arene Chemistry, D. Astruc (Ed.), pp. 196-216, Wiley-VCH, Weinheim (2002).

4. P. Manini, W. Amrein, V. Gramlich, F. Diederich. Angew. Chem., Int. Ed. 41, 4339-4343 (2002).

5. C. Lepetit, M. B. Nielsen, F. Diederich, R. Chauvin. Chem. Eur. J. 9, 5056-5066 (2003).

6. A. Auffrant, B. Jaun, P. D. Jarowski, K. N. Houk, F. Diederich. Chem. Eur. J. 10, 2906-2911 (2004).

7. F. Diederich. Nature 369, 199-207 (1994).

8. U. H. F. Bunz, Y. Rubin, Y. Tobe. Chem. Soc. Rev. 28, 107-119 (1999).

9. W. Krätschmer, L. D. Lamb, K. Fostiropoulos, D. R. Huffman. Nature 347, 354-358 (1990).

10. F. Diederich and M. Goméz-López. Chem. Soc. Rev. 28, 263-277 (1999).

11. F. Diederich and M. Goméz-López. Chimia 52, 551-556 (1998).

12. M. Prato (Ed.). Functionalized Fullerene Materials, special issue of J. Mater. Chem. 12, 1931-2159 (2002).

13. F. Diederich and R. Kessinger. Acc. Chem. Res. 32, 537-545 (1999).

14. F. Diederich and R. Kessinger. In Templated Organic Synthesis, F. Diederich and P. J. Stang (Eds.), pp. 189-218, Wiley-VCH, Weinheim (2000).

15. S. Sergeyev and F. Diederich. Angew. Chem., Int. Ed. 43, 1738-1740 (2004).

16. A. Hirsch. The Chemistry of the Fullerenes, Thieme, Stuttgart (1994).

17. F. Diederich and C. Thilgen. Science 271, 317-323 (1996).

18. J.-P. Bourgeois, P. Seiler, M. Fibbioli, E. Pretsch, F. Diederich, L. Echegoyen. Helv. Chim. Acta 82, 1572-1595 (1999).

19. M. van Eis, P. Seiler, L. A. Muslinkina, M. Badertscher, E. Pretsch, F. Diederich, R. J. Alvarado, L. Echegoyen, I. Pérez Núñez. Helv. Chim. Acta 85, 2009-2055 (2002).

20. M. Fibbioli, K. Bandyopadhyay, S.-G. Liu, L. Echegoyen, O. Enger, F. Diederich, D. Gingery, P. Bühlmann, H. Persson, U. W. Suter, E. Pretsch. Chem. Mater. 14, 1721-1729 (2002).

21. O. Enger, F. Nuesch, M. Fibbioli, L. Echegoyen, E. Pretsch, F. Diederich. J. Mater. Chem. 10, 2231-2233 (2000).

22. N. Papageorgiou, M. Grätzel, O. Enger, D. Bonifazi, F. Diederich. J. Phys. Chem. B 106, 3813-3822 (2002).

23. D. Bonifazi, A. Salomon, O. Enger, F. Diederich, D. Cahen. Adv. Mater. 14, 802-805 (2002).

24. D. Latassa, O. Enger, C. Thilgen, T. Habicher, H. Offermanns, F. Diederich. J. Mater. Chem. 12, 1993-1995 (2002).

25. P. Siemsen, R. C. Livingston, F. Diederich. Angew. Chem., Int. Ed. 39, 2632-2657 (2000).

26. R. R. Tykwinski and F. Diederich. Liebigs Ann./Recueil 649-661 (1997).

27. M. Nielsen and F. Diederich. Synlett 4, 544-552 (2002).

(C) 2005 IUPAC, Pure and Applied Chemistry 77, 1851-1863 
28. J.-P. Gisselbrecht, N. N. P. Moonen, C. Boudon, M. B. Nielsen, F. Diederich, M. Gross. Eur. J. Org. Chem. 2959-2972 (2004).

29. R. C. Livingston, L. R. Cox, V. Gramlich, F. Diederich. Angew. Chem., Int. Ed. 40, 2334-2337 (2001).

30. R. C. Livingston, L. R. Cox, S. Odermatt, F. Diederich. Helv. Chim. Acta 85, 3052-3077 (2002).

31. T. Lange, J.-D. van Loon, R. R. Tykwinski, M. Schreiber, F. Diederich. Synthesis 537-550 (1996).

32. J.-D. van Loon, P. Seiler, F. Diederich. Angew. Chem., Int. Ed. 32, 1187-1189 (1993).

33. M. J. Edelmann, S. Odermatt, F. Diederich. Chimia 55, 132-138 (2001).

34. M. J. Edelmann, M. A. Estermann, V. Gramlich, F. Diederich. Helv. Chim. Acta 84, 473-480 (2001).

35. R. E. Martin, U. Gubler, J. Cornil, M. Balakina, C. Boudon, C. Bosshard, J.-P. Gisselbrecht, F. Diederich, P. Günter, M. Gross, J.-L. Brédas. Chem. Eur. J. 6, 3622-3635 (2000).

36. J.-F. Nierengarten. Helv. Chim. Acta 87, 1357-1367 (2004).

37. Y. Takayama, C. Delas, K. Muraoka, M. Uemura, F. Sato. J. Am. Chem. Soc. 125, 14163-14167 (2003).

38. R. E. Martin and F. Diederich. Angew. Chem., Int. Ed. 38, 1350-1377 (1999).

39. E. Burri, F. Diederich, M. B. Nielsen. Helv. Chim. Acta 85, 2169-2182 (2002).

40. A. M. Boldi, J. Anthony, V. Gramlich, C. B. Knobler, C. Boudon, J.-P. Gisselbrecht, M. Gross, F. Diederich. Helv. Chim. Acta 78, 779-796 (1995).

41. Y. Zhao, R. McDonald, R. R. Tykwinski. J. Org. Chem. 67, 2805-2812 (2002).

42. P. Siemsen, U. Gubler, C. Bosshard, P. Günter, F. Diederich. Chem. Eur. J. 7, 1333-1341 (2001).

43. M. Mayor, C. von Hänisch, H. B. Weber, J. Reichert, D. Beckmann. Angew. Chem., Int. Ed. 41, 1183-1186 (2002).

44. R. R. Tykwinski, M. Schreiber, V. Gramlich, P. Seiler, F. Diederich. Adv. Mater. 8, 226-231 (1996).

45. R. Spreiter, C. Bosshard, G. Knöpfle, P. Günter, R. R. Tykwinski, M. Schreiber, F. Diederich.. J. Phys. Chem. B 102, 29-32 (1998).

46. H. Hopf and M. Kreutzer. Angew. Chem., Int. Ed. 29, 393-395 (1990).

47. L. Dulog, B. Körner, J. Heinze, J. Yang. Liebigs Ann. 1663-1671 (1995).

48. N. N. P. Moonen, C. Boudon, J.-P. Gisselbrecht, P. Seiler, M. Gross, F. Diederich. Angew. Chem., Int. Ed. 41, 3044-3047 (2002).

49. N. N. P. Moonen, R. Gist, C. Boudon, J.-P. Gisselbrecht, P. Seiler, T. Kawai, A. Kishioka, M. Gross, M. Irie, F. Diederich. Org. Biomol. Chem. 1, 2032-2034 (2003).

50. N. N. P. Moonen and F. Diederich. Org. Biomol. Chem. 2, 2263-2266 (2004).

51. H. Meier, B. Mühling, H. Kolshorn. Eur. J. Org. Chem. 1033-1042 (2004).

52. H. Meier, J. Gerold, H. Kolshorn, B. Mühling. Chem. Eur. J. 10, 360-370 (2004).

53. A. de Meijere and S. I. Kozhushkov. Chem. Eur. J. 8, 3195-3202 (2002).

54. Y. Tobe, R. Umeda, N. Isawa, M. Sonoda. Chem. Eur. J. 9, 5549-5559 (2003).

55. S. Eisler and R. R. Tykwinski. Angew. Chem., Int. Ed. 38, 1940-1943 (1999).

56. C.-H. Lin and J. Tour. J. Org. Chem. 67, 7761-7768 (2002).

57. D. Zhao and J. S. Moore. Chem. Commun. 807-818 (2003).

58. S. Höger, K. Bonrad, A. Mourran, U. Beginn, M. Möller. J. Am. Chem. Soc. 123, 5651-5659 (2001).

59. M. Mayor and C. Didschies. Angew. Chem., Int. Ed. 42, 3176-3179 (2003).

60. C. Grave and A. D. Schlüter. Eur. J. Org. Chem. 3075-3098 (2002).

61. T. Nishinaga, N. Nodera, Y. Miyata, K. Komatsu. J. Org. Chem. 67, 6091-6096 (2002).

62. W. B. Wan and M. M. Haley. J. Org. Chem. 66, 3893-3901 (2001).

63. T. Kawase, K. Tanaka, N. Fujiwara, H. R. Darabi, M. Oda. Angew. Chem., Int. Ed. 42, 1624-1628 (2003). 
64. M. Laskoski, W. Steffen, J. G. M. Morton, M. D. Smith, U. H. F. Bunz. J. Am. Chem. Soc. 124, 13814-13818 (2002).

65. J. Anthony, A. M. Boldi, C. Boudon, J.-P. Gisselbrecht, M. Gross, P. Seiler, C. B. Knobler, F. Diederich. Helv. Chim. Acta 78, 797-817 (1995).

66. M. B. Nielsen, M. Schreiber, Y. G. Baek, P. Seiler, S. Lecomte, C. Boudon, R. R. Tykwinski, J.-P. Gisselbrecht, V. Gramlich, P. J. Skinner, C. Bosshard, P. Günter, M. Gross, F. Diederich. Chem. Eur. J. 7, 3263-3280 (2001).

67. F. Mitzel, C. Boudon, J.-P. Gisselbrecht, P. Seiler, M. Gross, F. Diederich. Chem. Commun. 1634-1635 (2003).

68. J. Anthony, C. B. Knobler, F. Diederich. Angew. Chem., Int. Ed. 32, 406-409 (1993).

69. F. Mitzel, C. Boudon, J.-P. Gisselbrecht, M. Gross, F. Diederich. Chem. Commun. 2318-2319 (2002).

70. F. Mitzel, C. Boudon, J.-P. Gisselbrecht, P. Seiler, M. Gross, F. Diederich. Helv. Chim. Acta 87, 1130-1157 (2004).

71. A. M. Boldi and F. Diederich. Angew. Chem., Int. Ed. 33, 468-471 (1994).

72. M. Schreiber, R. R. Tykwinski, F. Diederich, R. Spreiter, U. Gubler, C. Bosshard, I. Poberaj, P. Günter, C. Boudon, J.-P. Gisselbrecht, M. Gross, U. Jonas, H. Ringsdorf. Adv. Mater. 9, 339-343 (1997).

73. H. Imahori, Y. Mori, Y. Matano. J. Photochem. Photobiol. C 3, 55-83 (2003).

74. N. Armaroli. Photochem. Photobiol. Sci. 2, $73-87$ (2003).

76. D. Gust, T. A. Moore, A. L. Moore. Acc. Chem. Res. 34, 40-48 (2001).

77. D. A. K. Burrell, D. L. Officer, P. G. Plieger, D. C. W. Reid. Chem. Rev. 101, 2751-2796 (2001).

78. D. M. Guldi and M. Prato. Acc. Chem. Res. 33, 695-703 (2000).

79. A. Tsuda, H. Furuta, A. Osuka. Angew. Chem., Int. Ed. 39, 2549-2552 (2000).

80. A.Tsuda and A. Osuka. Science 293, 79-82 (2001).

81. N. Aratani, A. Osuka, H. S. Cho, D. Kim. J. Photochem. Photobiol. C 3, 25-52 (2002).

82. D. Bonifazi and F. Diederich. Chem. Commun. 2178-2179 (2002).

83. D. Bonifazi, M. Scholl, F. Song, L. Echegoyen, G. Accorsi, N. Armaroli, F. Diederich. Angew. Chem., Int. Ed. 42, 4966-4970 (2003).

84. A. Graja, I. Olejniczak, A. Bogucki, D. Bonifazi, F. Diederich. Chem. Phys. 300, 227-232 (2004).

85. J.-P. Bourgeois, F. Diederich, L. Echegoyen, J.-F. Nierengarten. Helv. Chim. Acta 81, 1835-1844 (1998).

86. N. Armaroli, G. Marconi, L. Echegoyen, J.-P. Bourgeois, F. Diederich. Chem. Eur. J. 6, 1629-1645 (2000).

87. D. Bonifazi, H. Spillmann, A. Kiebele, M. de Wild, P. Seiler, F. Cheng, H.-J. Güntherodt, T. Jung, F. Diederich. Angew. Chem., Int. Ed. 43, 4759-4763 (2004).

88. S. Yoshimoto, E. Tsutsumi, Y. Honda, Y. Murata, M. Murata, K. Komatsu, O. Ito, K. Itaya. Angew. Chem., Int. Ed. 43, 3044-3047 (2004). 